Correction

\title{
Correction: 3D Bioprinting Technologies for Hard Tissue and Organ Engineering. Materials 2016, 9, 802
}

\author{
Xiaohong Wang ${ }^{1,2, *}$, Qiang Ao ${ }^{1}$, Xiaohong Tian ${ }^{1}$, Jun Fan ${ }^{1}$, Yujun Wei ${ }^{1}$, Weijian Hou ${ }^{1}$, \\ Hao Tong ${ }^{1}$ and Shuling Bai ${ }^{1}$ \\ 1 Department of Tissue Engineering, Center of 3D Printing \& Organ Manufacturing, \\ School of Fundamental Sciences, China Medical University (CMU), No. 77 Puhe Road, \\ Shenyang North New Area, Shenyang 110122, China; aoqiang00@163.com (Q.A.); \\ xhtian@cmu.edu.cn (X.T.); jfan@cmu.edu.cn (J.F.); Weiyj2011@gmail.com (Y.W.); \\ wjhou@cmu.edu.cn (W.H.); tongh007@hotmail.com (H.T.); baishuling@hotmail.com (S.B.) \\ 2 Department of Mechanical Engineering, Tsinghua University, Center of Organ Manufacturing, \\ Beijing 100084, China \\ * Correspondence: wangxiaohong709@163.com or wangxiaohong@tsinghua.edu.cn; Tel.: +86-189-0091-1302 \\ Academic Editor: Chee Kai Chua \\ Received: 7 November 2016; Accepted: 8 November 2016; Published: 10 November 2016
}

In the published manuscript "3D Bioprinting Technologies for Hard Tissue and Organ Engineering. Materials 2016, 9, 802 [1]", a reference (Ozbolat, I.T., Yu, Y. Bioprinting toward organ fabrication: challenges and future trends. IEEE Trans. Biomed. Eng. 2013, 60, 691-699) has been omitted from the references. Alterations are therefore requested to add this reference before the original reference 22 in the reference list, in the legend of Figure 2, as well as in the context (such as [17-23] in page 2 line 15, [12-23,26-28] in page 2 line 23). The following references after reference 22 therefore need to be changed. We apologize for the inconvenience this will have caused. In addition, the following changes to the text have been made:

Page 11, Section 3.3, the expression "such as stem cells" which appears six lines up from the bottom should be changed to "such as adipose-derived stem cells (ADSCs)".

Page 18, reference 46, the page range should be "298-310".

The changes do not affect the results. The manuscript will be updated and the original will remain online on the article webpage.

Conflicts of Interest: The authors declare no conflict of interest.

\section{Reference}

1. Wang, X.H.; Ao, Q.; Tian, X.H.; Fan, Y.; Wei, Y.; Hou, W.; Tong, H.; Bai, S. 3D Bioprinting Technologies for Hard Tissue and Organ Engineering. Materials 2016, 9, 802. [CrossRef]

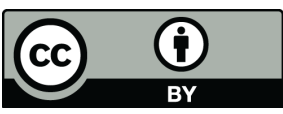

(C) 2016 by the authors; licensee MDPI, Basel, Switzerland. This article is an open access article distributed under the terms and conditions of the Creative Commons Attribution (CC-BY) license (http://creativecommons.org/licenses/by/4.0/). 